\title{
PERANAN VARIASI TEKANAN TERHADAP KARAKTERISTIK PEMBAKARAN SPRAY DENGAN CAMPURAN BAHAN BAKAR MINYAK KELAPA DAN MINYAK KAPUK (B50)
}

\author{
Teguh Yuli Ardiansah \\ Teknik Mesin, Fakultas Teknik \\ Universitas Maarif Hasyim Latif, Sidoarjo, Indonesia \\ e-mail : teguh-yuli-ardiansah@student.umaha.ac.id
}

\begin{abstract}
ABSTRAK
Dengan menipisnya ketersediaan bahan bakar fosil membuat para peneliti dari berbagai negara berlomba lomba mencari sumber energi alternatif yang dapat diperbarui salah satu ialah minyak nabati sumber minyak nabati didapat dari minyak kelapa dan minyak kapuk tanaman kelapa dan kapuk merupakan salah satu tumbuhan yang dapat digunakan untuk menghasilkan sumber energi alternatif hasil dari penelitian untuk mengetahui pengaruh variasi tekanan terhadap sudut spray panjang nyala api flashback nyala api diameter droplet pada minyak kelapa dan kapuk (B50) jenis nozzle yang dipake tipe cone dengan bahan stainles steel berdiameter $0,2 \mathrm{~mm}$ hasil yang diperoleh untuk mempercepat proses pembakaran menggunakan metode pembakaran spray menggunakan metode eksperimental dengan cara pembakaran spray bahan bakar yang digunakan minyak kelapa dan minyak kapuk dengan memvariasi tekanan 50 bar, 75 bar, dan 100 bar tekanan dihasilkan dari pompa jet cleaner pengambilan data ini dilakukan secara berulang ulang sampek untuk mendapatkan hasil yang maksimal semakin semakin meningkatnya tekanan mempengaruhi besarnya sudut spray dengan sudut $45,24^{\circ}$ sebaliknya kalau tekanan kecil sudutnya juga kecil yaitu $43,83^{\circ}$ perbedaan panjang nyala api dipengaruhi perbedaan variasi tekanan dengan hasil tekanan yang besar dengan panjang 1343,38 mm dan tekanan kecil dengan panjang 958,85 mm flashback dipengaruhi dari variasi tekanan terutama pada jarak $500 \mathrm{~mm}$ penyalaan awal dari nozzle sedangkan jarak $100 \mathrm{~mm}$ dan $900 \mathrm{~mm}$ penyalaan awal dari nozzle tidak terjadi penyalaan balik meningkatnya diameter droplet berbanding terbalik dengan meningkatnya tekanan dengan hasil pengukuran droplet yang bertekanan kecil 16,1 micron bertekanan besar 9,9 micron
\end{abstract}

Kata kunci: minyak nabati, panjang nyala api, pembakaran spray, sudut, tekanan

\section{PENDAHULUAN}

Ditengah menipisnya ketersediaan bahan bakar fosil, membuat para peneliti dari berbagai negara sedang gencar mencari sumber energi alternatif yang dapat diperbarui, salah satunya ialah minyak kelapa dan minyak kapuk. Tanaman kelapa dan kapuk merupakan salah satu tumbuhan yang dapat digunakan untuk menghasilkan sumber energi alternatif. Sumber energi yang dihasilkan dari tanaman ini berupa minyak murni yang berguna untuk menggantikan atau paling tidak mengurangi penggunaan bahan bakar yang sudah ada. Pada proses pembakaran minyak dirubah menjadi partikel dengan menggunakan nozzle kumpulan partikel akan membentuk sudut yang disebut sudut semburan penyebaran droplet tergantung dari sudut semburan yang dibentuk nozzle semakin besar sudut semburan maka semakin luas permukaan droplet untuk mengetahui hasil yang

Diperoleh maksimal maka penelitian ini dilakukan bertujuan untuk mencari pengaruh variasi tekanan terhadap sudut spray pengaruh variasi tekanan panjang nyala api pengaruh variasi tekanan flashback nyala api pengaruh variasi tekanan diameter droplet dengan menggunakan ukuran diameter nozzle yang sama

\section{METODE PENELITIAN}

Dalam proses pengerjaan penelitian dibutuhkan penyelesaian yang baik untuk memudahkan pengerjaan perencanaan penelitian setelah perancangan selesai maka akan dilakukan observasi dengan cara mensurvei bahan bakar minyak kelapa dan minyak kapuk yang didapat dari pohon kelapa dan pohon kapuk sebagai bahan bakar minyak nabati. kemudian melakukan penelitian ini yang bertujuan untuk mengetahui variasi tekanan terhadap sudut spray, nyala api, flashback nyala api, dan diameter droplet dengan menggunakan ukuran nozzle tetap

Dengan mempelajari penelitian sebelumnya tentang pemanfaatan minyak nabati. Data yang diperoleh merupakan data yang sudah dilakukan pengujian 1 sampai $10 \mathrm{kali}$, data yang sudah didapat kemudian diolah lagi menggunakan aplikasi yang sudah ada, setelah data yang sudah didapat maka selanjutnya penyusunan laporan dapat dilakukan. Adapun diagram alir penelitian ini pada gambar 2.1 sebagai berikut 


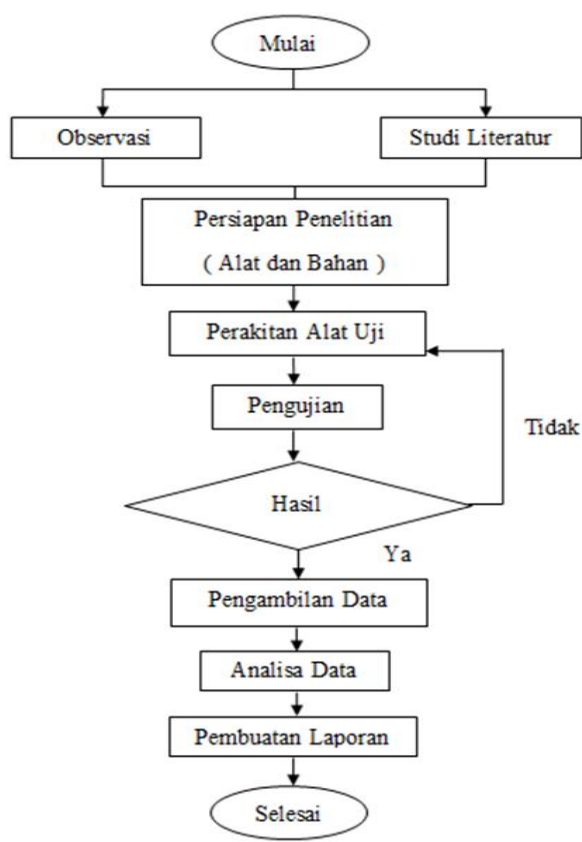

Gambar 2.1 Diagram alir penelitian

Alat :

1. Ember plastik

2. Pompa Jet Cleaner High Pressure

3. Selang Flexible

4. Bypass Valve

5. Pressure Gauge

6. Nozzle

7. Mistar

8. Lampu Sorot LED

9. Akrilik

10. Kamera

Bahan :

1. Minyak blending kelapa dan kapuk 6 liter

\section{Tempat dan waktu penelitian}

Persiapan bahan baku minyak dilakukan sebagai berikut:

1. Minyak kelapa dan minyak kapuk dibeli toko online

2. Penelitian ini dilakukan di Laboratorium Teknik Mesin Universitas Ma'arif Hasyim Latif yang beralamat di Jl. Raya Ngelom Megare No. 30 Megare, Taman. Sidoarjo - Jawa Timur. Dengan pembuatan alat kemudian dilanjutkan dengan penelitian.

\section{Langkah - langkah penelitian}

Alur penelitian ini menjadi 4 penelitian, setelah pembuatan alat yang sudah dibuat maka dilakukan penelitian pertama yaitu untuk mngetahui variasi tekanan terhadap sudut spray. Setelah dilakukan penelitian yang pertama maka diteruskan dengan yang kedua yaitu untuk mengetahui variasi tekanan terhadap panjang nyala api, maka dilanjutkan ketiga yaitu untuk mengetahui variasi tekanan terhadap flashback nyala api kemudian yang keempat yaitu untuk mengetahui variasi tekanan terhadap ukuran diameter droplet.

Ada 3 macam tekanan yang dipakai dalam penelitian ini dengan meggunakan tekanan 50 bar, 75 bar, 100 bar dengan menggunakan ukuran nozzle 0,2 mm. Berikut merupakan rangakaian yang digunakan ditunjukkan dengan gambar 2.2

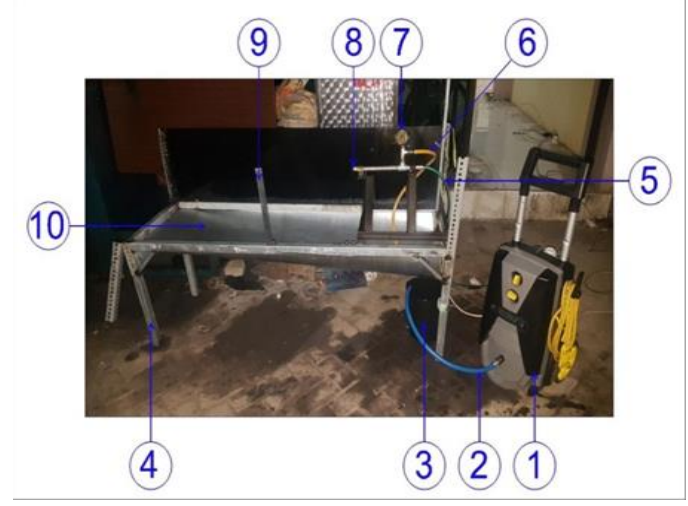

Gambar 2.2 Instalasi alat pengujian

Adapun pompa yang dipakai adalah pompa yang biasa dipakai ditempat cuci mobil atau sepeda dan dibeli ditoko pompa dengan kapasitas \pm 150 bar dengan mengunakan tenaga listrik. Dengan nozzle yang dipakai diperoleh dengan cara memesan ketukang bubut serta alat sisanya dibeli ditoko sekitar tempat pengujian.

\subsection{Penelitian 1}

Penelitian ini dilakukan untuk mengetahui variasi tekanan terhadap sudut spray. Setelah proses penelitian yang dilakukan dengan cara melakukan video. Akan diteruskan dengan mengolah hasil penelitian tersebut menggunakan program aplikasi free video to jpg coverter, Image J, dan Corel Draw.

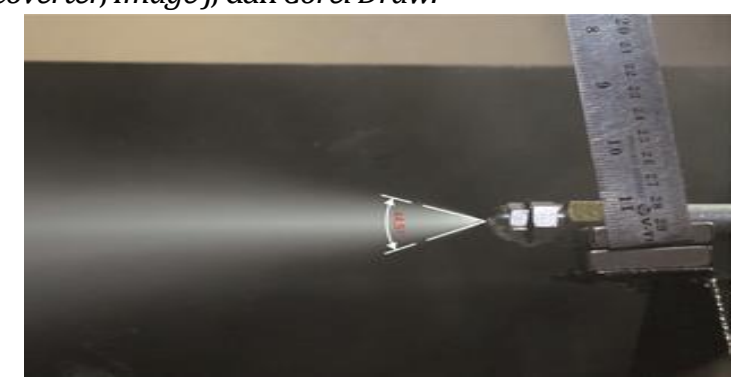

Gambar 2.3 Proses pengambilan data sudut spray

\subsection{Penelitian 2}

Penelitian ini untuk mengetahui variasi tekana terhadap panjang nyala api. Setelah dilakukan penelitian dengan cara video penelitian tersebut maka akan diteruskan dengan menggunakan program aplikasi free video to jpg coverter, Image J, dan Corel Draw.

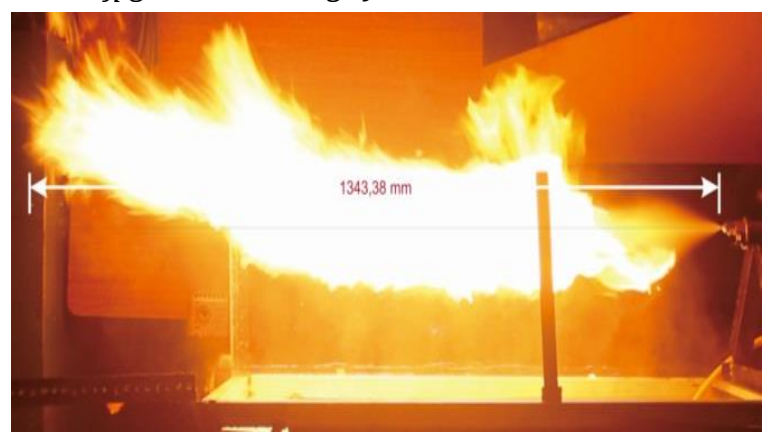

Gambar 2.4 Proses pengambilan data panjang nyala api 


\subsection{Penelitian 3}

Penelitian ini untuk mengetahui variasi tekanan terhadap flashback nyala api

Setelah melakukan penelitian ini dengan cara video hasil penelitian diteruskan dengan cara mengolah data dengan program aplikasi free video to jpg coverter, Image J, dan Corel Draw.

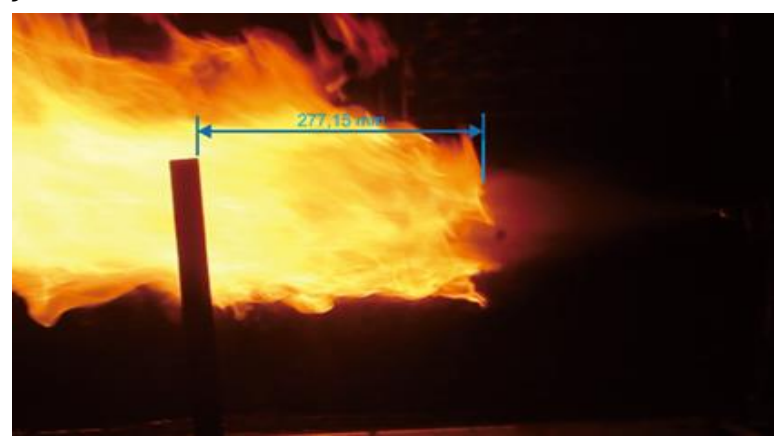

Gambar 2.4 Proses pengambilan data flashback nyala api

\subsection{Penelitian 4}

Penelitian untuk mengetahui variasi tekanan terhadap diameter droplet. Untuk penelitian beda dari yang sebelumnya dikarenakan penelitian ini dilakukan dengan menggunakan rumus reynolds number dan webber number yang sudah diterapkan

\section{HASIL DAN PEMBAHASAN}

\section{Rumus Perhitungan Droplet}

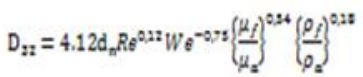

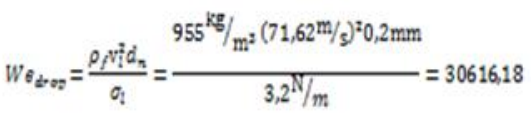

$$
\begin{aligned}
& \text { Dimena: } \\
& \sigma_{f} \quad=3,2 \mathrm{~N} / \mathrm{m} \\
& \text { of }=955 \mathrm{~kg} / \mathrm{m}^{2} \\
& \rho_{\mathrm{a}}=1,2 \mathrm{~kg} / \mathrm{m}^{2} \\
& v_{f}=50,55 \mathrm{~mm}^{2} / \mathrm{s} \\
& v_{f}=65,49 \mathrm{~m} / \mathrm{s} \\
& \mathrm{d}_{\mathrm{n}}=0,2 \mathrm{~mm} \\
& \mu_{f}=32 \mathrm{Ns} / \mathrm{m}^{2} \\
& \mu_{\mathrm{a}}=0,89 \mathrm{Ns} / \mathrm{m}^{2}
\end{aligned}
$$

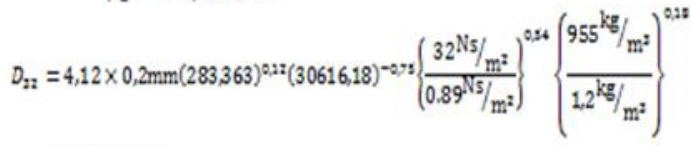

$$
\begin{aligned}
& =0,0161 \mathrm{~mm} \\
& 0,0161 \times 1000=16,1 \text { micron }
\end{aligned}
$$

\subsection{Penelitian 1}

Hasil dari penelitian diketahui ukuran secara teoritis dan secara eksperimen

Tabel 3.1 Sudut spray variasi tekanan

\begin{tabular}{|l|l|l|l|l|}
\hline No & $\begin{array}{c}\text { Nozzle } \\
\text { (mm) }\end{array}$ & $\begin{array}{l}\text { Tekanan } \\
\text { (bar) }\end{array}$ & $\begin{array}{l}\text { Sudut } \\
\text { akt(0) }\end{array}$ & $\begin{array}{l}\text { Sudut } \\
\text { teo(0) }\end{array}$ \\
\hline 1 & 0,2 & 50 & 43,83 & 40,9 \\
\hline 2 & 0,2 & 75 & 44,51 & 43,1 \\
\hline 3 & 0,2 & 100 & 45,24 & 45,17 \\
\hline
\end{tabular}

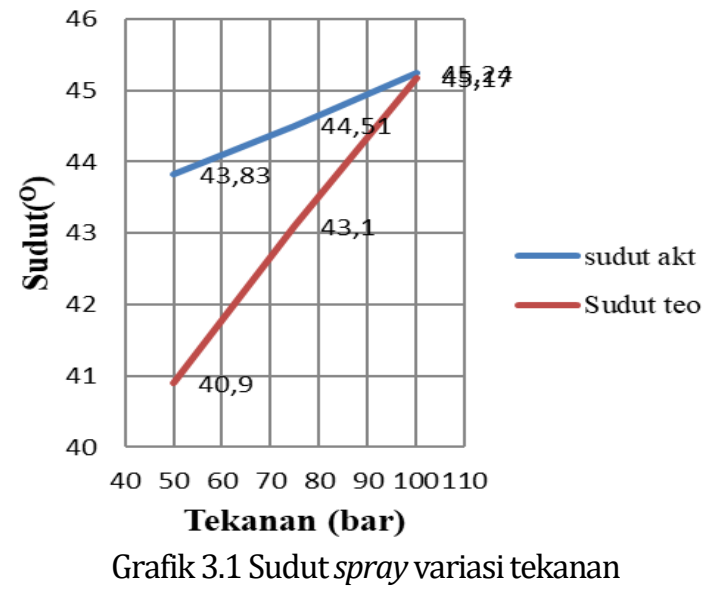

Tekanan dari 50 bar dirubah menjadi tekanan 75 bar dan ditingkatkan menjadi tekanan 100 bar telah terjadi perubahan sudut spray. Sudut droplet paling kecil terjadi pada tekanan sebesar 50 bar dengan sudut sebesar 43,83o, lebih kecil jika dibandingkan dengan tekanan 100 bar sebesar 45,24\%.

Antara sudut actual dengan sudut secara teoritis. Dimana sudut secara actual lebih besar dibandingkan sudut hasil perhitungan secara teori.

Hal tersebut bisa dipengaruhi karena tegangan permukaan minyak nabati saat melewati lubang nozzle. Semakin besar tekanannya menurunkan tegangan permukaan minyak nabati yang melewati lubang nozzle tersebut

\subsection{Penelitian 2}

Hasil pengujian secara teoritis dan eksperimen panjang nyala api terhadap variasi tekanan

Tabel 3.2 Panjang nyal api variasi tekanan

\begin{tabular}{|l|l|l|l|l|}
\hline No & $\begin{array}{c}\text { Nozzle } \\
\text { (mm) }\end{array}$ & $\begin{array}{c}\text { Tekanan } \\
\text { (bar) }\end{array}$ & $\begin{array}{c}\text { Panjang } \\
\text { (mm) }\end{array}$ & $\begin{array}{c}\text { Debit } \\
\text { (mm) }\end{array}$ \\
\hline 1 & 0,2 & 50 & 958,85 & 2220 \\
\hline 2 & 0,2 & 75 & 1196,62 & 2719 \\
\hline 3 & 0,2 & 100 & 1343,38 & 3139 \\
\hline
\end{tabular}

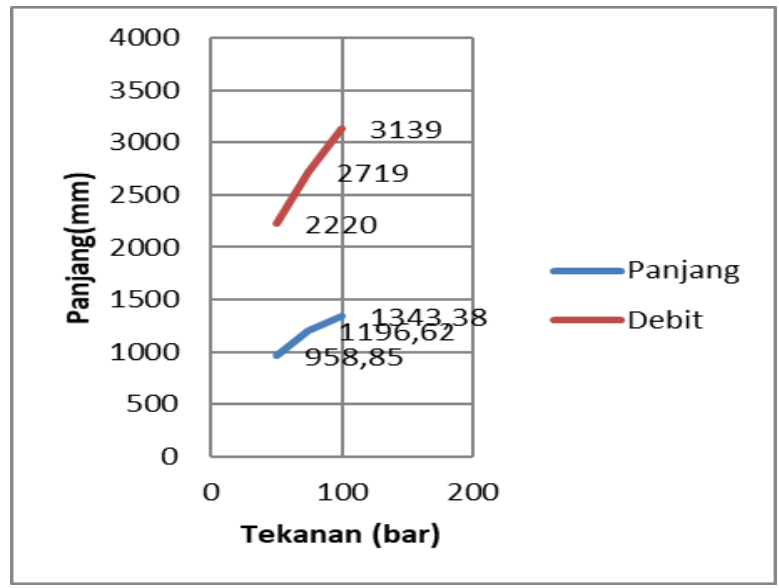

Grafik 3.2 Panjang nyala api variasi tekanan 
Pada grafik dan tabel tersebut terlihat bahwa semakin besar tekanan tehadap nozzle sangat berpengaruh pada nyala api yang di terjadi, bertambahnya panjang nyala api terjadi karena dipengaruhi oleh debit bahan bakar yang melewati lubang nozzle.

Dari hasil perhitungan secara teoritis debit bahan bakar paling kecil terdapat pada tekanan sebesar 50 bar dimana debit yang keluar melewati lubang nozzle sebesar 2,220 $\mathrm{m}^{3} / \mathrm{s}$ sedangkan debit paling besar terjadi pada tekanan 100 bar yakni $3,139 \mathrm{~m}^{3} / \mathrm{s}$.

\subsection{Penelitian 3}

Hasil pengujian variasi tekanan terhadap ukuran diameter droplet. Pada penelitian tekanan 50 bar, 75 bar, 100 bar dengan ukuran nozzle 0,2 mm jarak $100 \mathrm{~mm}$ diketahui bahwa tidak terjadi flashback pada saat pemantik menyalakan api berada pada posisi $100 \mathrm{~mm}$ yang ditandai pada penggaris yang sudah diukur sebelumnya.

Pada tekanan 50 bar nyala api terjadi dibelakang penggaris, pada saat tekanan terhadap nozzle kemudian tekanan diperbesar menjadi 75 bar dimana nyala api berada dibelakang penggaris. Pada saat tekanan dinaikkan lagi menjadi 100 bar nyala api juga berada dibelakang penggaris dan tidak terjadi flashback.

Pada variasi tekanan 50 bar, 75 bar, 100 bar dengan ukuran nozzle $0,2 \mathrm{~mm}$ menunjukan telah terjadi flashback disaat pemantik api dinyalakan berada pada posisi $500 \mathrm{~mm}$ yang ditandai dengan penggaris yang diukur sebelumnya. Pada tekanan 50 bar jarak $500 \mathrm{~mm}$ nyala api terjadi pada $277,15 \mathrm{~mm}$ didepan penggaris, saat tekanan terhadap nozzle diperbesar menjadi 75 bar dimana Panjang nyala api flashback pada tekanan 75 bar sebesar 42,9 mm.

Sedangkan saat tekanan dinaikkan kembali menjadi 100 bar ujung nyala api flashback semakin mendekat ke nosel pada posisi 486,79 $\mathrm{mm}$ dibelakang penggaris. Pada posisi pemantik $500 \mathrm{~mm}$ terjadi flashback yang cukup panjang. Saat tekanan nozzle sebesar 50 bar terjadi flashback sepanjang 277,15 mm semakin tekanan diperbesar terjadi peningkatan yang cukup signifikan.

Hal ini menunjukkan bahwa pada posisi $500 \mathrm{~mm}$ di depan penggris bahan bakar sudah berbentuk droplet yang sempurna sehingga dapat terjadi flashback yang cukup panjang.

Pada penelitian variasi tekanan 50 bar, 75 bar, 100 bar dengan ukuran nozzle 0,2 mm menunjukkan bahwa tidak terjadi nyala api flashback pada posisi pemantik di $900 \mathrm{~mm}$ dari ujung nozzle. Bahan bakar tidak bisa terbakar secara stabil, dikarenakan untuk menyalakan api dibutuhkan waktu yang cukup lama agar terjadi nyala api. Pada tekanan 50 bar menunjukkan hanya terjadi ledakan kecil saat tekanan dinaikkan lagi terdapat peningkatan nyala api namun tidak sampai terjadi flashback.
Tabel 3.3 Pengujian variasi tekanan terhadap

\begin{tabular}{|c|c|c|c|c|c|}
\hline \multirow{3}{*}{$\begin{array}{l}\mathbf{N} \\
\mathbf{0}\end{array}$} & & flash & znyale & & \\
\hline & \multirow[t]{2}{*}{$\begin{array}{c}\text { Tekan } \\
\text { an } \\
\text { (bar) }\end{array}$} & \multirow[t]{2}{*}{$\begin{array}{c}\text { Nozz } \\
e l \\
(\mathrm{~mm} \\
)\end{array}$} & \multicolumn{3}{|c|}{ Flashback } \\
\hline & & & $\begin{array}{l}100 \mathrm{~m} \\
\mathrm{~m}\end{array}$ & $\begin{array}{l}500 \mathrm{~m} \\
\mathrm{~m}\end{array}$ & $\begin{array}{l}900 \mathrm{~m} \\
\mathrm{~m}\end{array}$ \\
\hline 1 & 50 & 0,2 & 0 & 277,15 & 0 \\
\hline 2 & 75 & 0,2 & 0 & 320,05 & 0 \\
\hline 3 & 100 & 0,2 & 0 & 486,79 & 0 \\
\hline
\end{tabular}

\subsection{Penelitian 4}

Karena keterbatasan alat untuk mengukur droplet secara actual, maka untuk mengetahui besar butiran dropletyang terbentuk hasil dariatomisasi bahan bakar dapat diperkirakan menggunakan persamaan Sauter Mean Diameter atau $\mathrm{D}_{32}$ berikut :

$\mathrm{D}_{32}=4.12 \mathrm{~d}_{\mathrm{n}} R e^{0,12} W e^{-0,75}\left\{\frac{\mu_{f}}{\mu_{a}}\right\}^{0,54}\left\{\frac{\rho_{f}}{\rho_{a}}\right\}^{0,18}$

Agar persamaan diatas bisa ditentukan nilainya maka harus ditentukan terlebih dahulu nilai Reynolds number (Re) spray dan Weber number (We) droplet. Dimana nilai Reynolds number dapat ditentukan menggunakan persamaan :

$R e_{\text {sprayy }}=\frac{\mathrm{v}_{f} d_{n}}{v_{f}}=\frac{71,62 \mathrm{~m} / \mathrm{s} \times 0,2 \mathrm{~mm}}{50.55 \mathrm{~mm}^{2} / \mathrm{s}}=283,363$

Sedangkan nilai Weber number dapat ditentukan menggunakan rumus persamaan :

$$
\begin{aligned}
W e_{\text {drop }}=\frac{\rho_{f} \mathrm{v}_{l}^{2} d_{n}}{\sigma_{l}} & \\
& =\frac{955 \mathrm{~kg} / \mathrm{m}^{3}(71,62 \mathrm{~m} / \mathrm{s})^{2} 0,2 \mathrm{~mm}}{3,2 \mathrm{~N} / \mathrm{m}} \\
& =30616,18
\end{aligned}
$$

Dimana:

$$
\begin{array}{ll}
\sigma_{f} & =3,2 \mathrm{~N} / \mathrm{m} \\
\rho_{f} & =955 \mathrm{~kg} / \mathrm{m}^{3} \\
\rho_{a} & =1,2 \mathrm{~kg} / \mathrm{m}^{3} \\
v_{f} & =50,55 \mathrm{~mm}^{2} / \mathrm{s} \\
\mathrm{v}_{f} & =65,49 \mathrm{~m} / \mathrm{s} \\
\mathrm{d}_{\mathrm{n}} & =0,2 \mathrm{~mm} \\
\mu_{f} & =32 \mathrm{Ns} / \mathrm{m}^{2} \\
\mu_{a} & =0,89 \mathrm{Ns} / \mathrm{m}^{2}
\end{array}
$$

Karena nilai Reynolds number dan weber number sudah diketahui maka untuk mencari dimensi droplet adalah

$$
\begin{aligned}
& D_{32}=4,12 \times 0,2 \mathrm{~mm}(283,363)^{0,12}(30616,18)^{-0,75} \\
& \left\{\frac{32^{\mathrm{Ns}} / \mathrm{m}^{2}}{0.89^{\mathrm{Ns}} / \mathrm{m}^{2}}\right\}^{0,54}\left\{\frac{955^{\mathrm{kg}} / \mathrm{m}^{3}}{1,2^{\mathrm{kg}} / \mathrm{m}^{3}}\right\}^{0,18}=0,0161 \mathrm{~mm} \\
& 0,0161 \times 1000=16,1 \text { micron }
\end{aligned}
$$


$D_{32}=4,12 \times 0,2 \mathrm{~mm}(347,062)^{0,12}(45927,81)^{-0,75}$ $\left\{\frac{32^{\mathrm{Ns}} / \mathrm{m}^{2}}{0.89^{\mathrm{Ns}} / \mathrm{m}^{2}}\right\}^{0,54}\left\{\frac{955^{\mathrm{kg}} / \mathrm{m}^{3}}{1,2^{\mathrm{kg}} / \mathrm{m}^{3}}\right\}^{0,18}=0,0121 \mathrm{~mm}$ $0,0121 \times 1000=12,1$ micron

$D_{32}=4,12 \times 0,2 \mathrm{~mm}(400,751)^{0,12}(61237,18)^{-0,75}$ $\left\{\frac{32^{\mathrm{Ns}} / \mathrm{m}^{2}}{0.89^{\mathrm{Ns}} / \mathrm{m}^{2}}\right\}^{0,54}\left\{\frac{955^{\mathrm{kg}} / \mathrm{m}^{3}}{1,2^{\mathrm{kg} / \mathrm{m}^{3}}}\right\}^{0,18}=0,0099 \mathrm{~mm}$ $0,0099 \times 1000=9,9$ micron

Tabel 3.4 Ukuran perhitungan variasi tekanan diameter

\begin{tabular}{|l|l|l|l|}
\hline \multicolumn{4}{|c|}{ droplet } \\
No & $\begin{array}{l}\text { Nozzle } \\
\text { (mm) }\end{array}$ & $\begin{array}{l}\text { Tekanan } \\
\text { (bar) }\end{array}$ & $\begin{array}{l}\text { Droplet } \\
\text { (micron) }\end{array}$ \\
\hline 1 & 50 & 0,2 & 16,1 \\
\hline 2 & 75 & 0,2 & 12,1 \\
\hline 3 & 100 & 0,2 & 9,9 \\
\hline
\end{tabular}

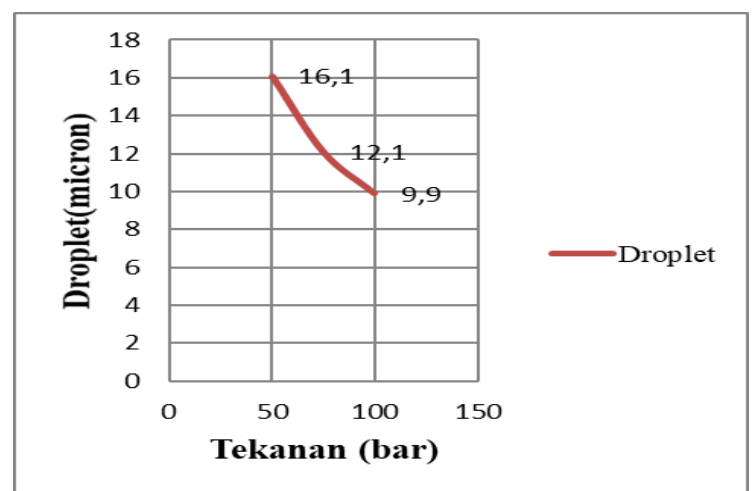

Grafik 3.3 Ukuran perhitungan variasi tekanan terhadap diameter droplet

Pada grafik dan tabel tersebut terlihat bahwa semakin besar tekanan tehadap nozzle sangat berpengaruh pada diameter droplet yang terjadi, penurunan diameter droplet terjadi karena dipengaruhi oleh tekanan.

\section{PENUTUP}

Dari hasil pengujian didapat bahwa secara umum variasi tekanan terhadap nyala api dengan menggunakan bahan bakar minyak kelapa dan minyak kapuk B50 adalah :

1. Semakin meningkatnya tekanan mempengaruhi besarnya sudut spray sebaliknya kalau tekanan kecil sudutnya juga kecil.

2. Panjang nyala api dipengaruhi perbedaan variasi tekanan.

3. flashback dipengaruhi dari variasi tekanan terutama pada jarak $500 \mathrm{~mm}$ penyalaan awal dari nozzle sedangkan jarak $100 \mathrm{~mm}$ dan $900 \mathrm{~mm}$ penyalaan awal dari nozzle tidak terjadi penyalaan balik.

4. Meningkatnya diameter droplet berbanding terbalik dengan meningkatnya tekanan.

\section{DAFTAR PUSTAKA}

Adam, A., Rizalman, M., \& Yatsufusa, T. (2015). Analysis of Diesel Spray Droplets Behavior Using Shadowgraph Technique Images. International Journal of Materials, Mechanics and Manufacturing, 3(1), 60-64. https://doi.org/10.7763/ijmmm.2015.v3.16 7

Aziz, I. (2008). Pembuatan Biodiesel Dari Minyak Goreng Bekas Dalam Reaktor Tangki Alir Berpengaduk. Jurnal Kimia VALENSI, 1(2). https://doi.org/10.15408/jkv.v1i2.257

Afifah, Y. N. (2016). ALIRAN TAK TUNAK FLUIDA NANO MAGNETOHIDRODINAMIK ( MHD ) YANG MELEWATI BOLA.

Afifah, Y. N. (2019). (2019). Analysis of Unsteady Magneto Hydro Dynamic ( MHD ) Nano Fluid Flow Past A Sliced Sphere Analysis of Unsteady Magneto Hydro Dynamic ( MHD ) Nano Fluid Flow Past A Sliced Sphere. IOP Conference Series: Materials Science and Engineering, 494, 012033. https://doi.org/10.1088/1757899X/494/1/012033

Afifah, Y. N., \& Putra, B. C. (2018). Model Matematika Aliran Tak Tunak Pada Nano Fluid Melewati Bola Teriris Dengan Pengaruh Medan Magnet. Teknika: Engineering and Sains Journal, 2(2), 119-124.

Deshmukh, D., Madan Mohan, A., Anand, T. N. C., \& Ravikrishna, R. V. (2012). Spray characterization of straight vegetable oils at high injection pressures. Fuel, 97(July), 879883.

https://doi.org/10.1016/j.fuel.2012.01.078

Equipment, E. (2013). Concept and Theory Training. 24-25.

Ergianto, M. D., Ghurri, A., Gede, I. D., \& Swastika, P. (2018). Pengaruh Tekanan Injeksi terhadap Tingkat Atomisasi dan Karakteristik Spray pada Airblast Atomizer. 7(4), 312-315.

Gunawan, E. et al. (2019) 'Analysis of the Effect of Current Flow Variations in GTAW on SS 400 Plate Material Connected with SUS 304 Stainless Steel Plate Against Tensile Strength and Hardness with ER308L Electrodes', Journal of Physics: Conference Series, 1175(1). doi: 10.1088/1742-6596/1175/1/012277.

I Wayan Suma Wibawa, Kusuma, I. G. B. W., \& Budiarsa, I. N. (2015). Uji Variasi Tekanan Nosel Terhadap Karakteristik Semprotan Bahan Bakar Biodiesel. 1(2), 35-44.

Indonesia, U., Mahandari, C. P., Teknik, F., Pasca, P., \& Teknik, S. (2010). FENOMENA FLAME LIFTUP FENOMENA FLAME LIFT-UP.

Ismarani , Salih Muharam, S. N. (2011). KARAKTERISASI DAN KOMPOSISI BIODIESEL DARI MINYAKJARAK PAGAR (jatropha curcas 
L. ) Ismarani, Salih Muharam, Sulung Nomosatryo Abstract. 2(2).

Juniarta, I. K., Wirawan, I. K. G., \& Ghurri, A. (2017). Studi Eksperimental Pengaruh Variasi Tekanan Terhadap Sudut Semburan Minyak Jelantah. 6(2), 2-6.

Kewas, J. C. (2006). Pengaruh Variasi Persentase Minyak Kelapa pada Bahan Bakar Solar terhadap Sudut dan Intermitensi Atomisasi The Impacts of Coconut Oil Percentage Toward Diesel Fuel to the Angle and Intermittent of Atomization. 94-97.

Novilla, A., Nursidika, P., \& Mahargyani, W. (2017). Komposisi Asam Lemak Minyak Kelapa Murni (Virgin Coconut Oil) yang Berpotensi sebagai Anti Kandidiasis. EduChemia (Jurnal Kimia Dan Pendidikan), 2(2), 161. https://Putra, B. C., \& Afifah, Y. N. (2018). Gaussian Mixture Model Untuk Penghitungan Tingkat. Teknika: Engineering and Sains Journal, 2, 53-58.

Putra, B. C., \& Afifah, Y. N. (2018) 'Gaussian Mixture Model Untuk Penghitungan Tingkat', Teknika: Engineering and Sains Journal, 2, pp. 53-58.

Yunita Nur Afifah, MNH Qomarudin, \& Imamatul Ummah. (2020). Optimal Control Model Pemanenan Prey-Predator di Area Konservasi Ikan. Buana Matematika: Jurnal Ilmiah Matematika Dan Pendidikan Matematika, 10(1), 1-16. https://doi.org/10.36456/buanamatematika. v10i1.2410 